\title{
Cumulative incidence and causal risk factors of carcass condemnations in a South African high-throughput cattle abattoir
}

\author{
E.C. Webb ${ }^{1 \#}$, E.M. Webb ${ }^{2}$ \& P.T. Tlhapi ${ }^{1}$ \\ ${ }^{1}$ Department of Animal and Wildlife Sciences, Faculty of Natural and Agricultural Sciences, University of Pretoria, \\ Pretoria 0002, South Africa \\ ${ }^{2}$ School of Health Systems and Public Health, Faculty of Health Sciences, University of Pretoria, Pretoria 0002, South \\ Africa
}

(Received 4 July 2019; Accepted 4 December 2019; First published online 17 March 2020)

\begin{abstract}
Copyright resides with the authors in terms of the Creative Commons Attribution 4.0 South African License.
See: http://creativecommons.org/licenses/by/4.0/za

Condition of use: The user may copy, distribute, transmit and adapt the work, but must recognize the authors and the South African Journal of Animal Science.
\end{abstract}

\begin{abstract}
Carcass condemnation is a problem in the South African beef industry, but the causes and risk factors have not been studied or quantified. Better understanding of the cumulative incidence and causative predictors of carcass condemnations could assist in improving cattle management during transportation, preslaughter and lairage in high-throughput abattoirs. This study was conducted to investigate the main causes and predisposing factors of carcass condemnation at a large high-throughput cattle abattoir during postmortem inspections from January to December 2010. The experimental design included the effects of season, breed type, and sex, and their interactions on the cumulative incidence of carcass condemnations, and the causes of partial and whole carcass condemnations and the impact on carcass yield. The model was based on the presence of defects. Thirteen diseases and defects were evaluated in various breeds, sexes and seasons. The cumulative incidence of partial and complete carcass condemnations was $9.5 \%$. The most important causes were peritonitis and pleuritis, soiling and bruising, Almost half of these carcass condemnations were due to soiling and bruising, which can be addressed by implementing better abattoir management during transportation, pre-slaughter and lairage. The cumulative incidence of parafilaria occurred mostly in spring and summer. Measles, intramuscular haemorrhage and wet carcass syndrome occurred mostly in winter. The cumulative incidence of the other defects had a negligible effect. Numerically the greatest carcass weight losses subsequent to partial condemnations were because of intramuscular haemorrhage and bruising.
\end{abstract}

Keywords: abattoir management, breed, carcass condemnation, cattle, seasonal effects, sex

\#Corresponding author: edward.webb@up.ac.za

\section{Introduction}

The inspection of beef carcasses is carried out routinely in South African abattoirs to diagnose animal diseases and defects in all slaughter stock that may result in carcasses being deemed unfit for human consumption. The cumulative incidence during this routine surveillance may be defined as the number of new cases of condemnations, divided by the number of animals at risk at the start of the period. Carcass condemnations cause huge economic losses to the beef industry (Mummed \& Webb, 2015), and are a mounting problem in the South African beef industry. The importance of the management of cattle slaughter is generally appreciated, but a better understanding of the main causes of carcass condemnation and the effects of season, breed type, and sex on the cumulative incidence of carcass condemnations may help to improve slaughter management at local abattoirs.

Abattoirs serve as a reference centre for the cumulative incidence of diseases to avoid condemnation of carcasses during the post-mortem period. Meat inspection is conducted at abattoirs to screen and identify animal products with abnormal pathological lesions that are unsafe for human consumption. Meat inspection serves an essential contrivance to detect certain diseases and conditions of livestock through control measures to prevent the distribution of infected meat that could give rise to zoonotic diseases (Mohammed et al., 2012). Cattle are generally susceptible to diseases and injury. For example, measles are caused by tapeworms, which may result in carcass condemnation. Parafilaria causes a greenish and watery layer on 
the surface of the carcass post mortem. Muscular discoloration may also result from injuries and lead to blood clots, causing intramuscular haemorrhage post mortem, which may lead to condemnation of carcasses.

The transport of live animals is generally one of the major stressors for livestock, which have to be transported to farms, auctions and abattoirs (Warris et al., 1995; Mach et al., 2008). Previous studies confirmed the strong relationship between pre-slaughter cattle management and carcass damage (Warris et al., 1995; Grigor et al., 1997; Mach et al., 2008). Factors such as time off feed, water deprivation, and mixing of foreign cattle often result in behavioural problems, especially in the sale yard and lairage (Blackshaw et al., 1987). Transportation over longer distances may result in more stress and physical damage (Gallo et al., 2003). Most injuries that are inflicted from aggressive cattle behaviour are caused by horns, handling facilities and vehicle obstruction (Minka \& Ayob, 2007). Rough animal handling, soiling of hides, poor resting, and diseases such as transit fever increase the risk of carcass bruising and cause significant production and financial losses (Smith \& Wilson, 2000). These researchers rightly argue that carcass condemnations can be reduced or eliminated by better feedlot, transportation, and abattoir management.

Mud and manure are of concern in the contamination of carcasses, especially when they are present on the legs and belly of animals, and may be transferred inadvertently to carcasses during slaughter. Such contamination of beef carcasses represents a risk of microbial contamination during slaughter (BoghSorensen, 1980), and different methods are employed to reduce microbial contamination such as top-down slaughter procedures and washing methods. Washing methods have been identified as a potential risk, since washing may cause additional contamination if not conducted hygienically. The instruments used in slaughter and dressing also may be sources of contamination. Hygienic practices, including frequent handwashing and knife sterilization, must be followed properly during removal of the hide. Contact between the carcass and the hide must be prevented. Dirty hands, hooks, rollers, and protective clothing can contaminate carcasses while removing the hide and this must be prevented at all costs (Van der Walt, 2005).

Different breed types of cattle in South Africa (e.g. Afrikander, Bonsmara, Friesland, and Nguni) are likely to be affected by different diseases and conditions due to regional differences in climate, disease conditions and management practices. A number of intrinsic and extrinsic factors influence the behaviour of bovines including breed type, sex, physiological status, production system, seasonal and environmental factors (Phillips, 1993). Any odd or abnormal behaviour increases the risk of injury and may have detrimental effects on carcass characteristics (Grandin, 1989). The aim of this study was to investigate the main causes of carcass condemnation and the effects of season, breed type, and sex on the cumulative incidence of carcass condemnations in a large South African abattoir.

\section{Materials and Methods}

Data were collected in a high throughput Grade A beef abattoir. A total of 25590 carcasses from different cattle breed types were evaluated through standard carcass inspection from January to December 2010 (spring, summer, autumn and winter). A total of 18 causes of carcass condemnations and defects were recorded, but data of only the 13 most prevalent ones were analysed because of insufficient data on the other defects. Data from summer and spring were combined because of the absence of significant differences between these seasons. Daily inspections and observations of carcasses were performed and these records were kept: number of cattle slaughtered, season and date of slaughter, breed type, number of bulls and heifers, condemnations, description of defects and diseases diagnosed.

Carcasses were inspected for abnormalities, and affected carcasses or organs were detained for secondary meat inspection by a certified meat inspector (Meat Safety Act, Act 40 of 2000). Approved carcasses are normally marked with a 'passed' stamp, which certifies that carcass inspection has been done and the product is safe for human consumption. Primary inspection was conducted by six meat inspectors on rotation so that each could have a one-hour break, keeping their assessments as accurate as possible. Observation of carcasses was done visually and palpation was done where necessary. Other conditions and diseases were referred for secondary inspection by a veterinarian. Some carcasses were partially condemned and some were totally condemned. Diseases and defects observed during the study were abscesses, arthritis, bruising, emaciation, fever, intramuscular haemorrhage, jaundice, measles, oedema, peritonitis and pleuritis, soiling, parafilaria, and wet carcass syndrome.

The model used in analysis of the binary response indicating the presence of a defect data included the effects of season (S), breed type (B) and sex (G).

$$
\log \left(\frac{P}{1-P}\right) Y=\mu+a_{i}+\beta_{j}+\gamma_{k}
$$

Where: $P=$ Probability of the presence of condition $Y$, 


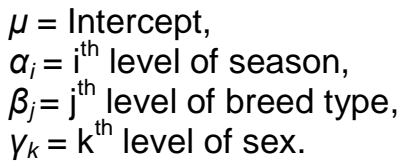

The epidemiological Bradford-Hill criteria were used to distinguish between associated and causal effects (Hill, 1965). The effects of season on the various causes of partial or total carcass condemnation were analysed with the general linear model ANOVA procedure of SAS version 9.2 (SAS Institute Inc., 2017. Cary, North Carolina, USA.). Effects were considered significant at $P<0.05$. Regression analyses were performed on carcass weight, season (month), and the percentage of carcass weight losses due to partial carcass condemnations.

\section{Results and Discussion}

A total of 25590 carcasses from various cattle breed types were inspected and the proportional composition of bulls to cows reflected the normal large proportion of young bulls slaughtered relative to cows (Table 1). Most of the cattle originated from large feedlot systems in the region, with an average live weight of $460 \mathrm{~kg}$ and yielding carcasses of $264 \pm 39.3 \mathrm{~kg}$. The majority of cattle slaughtered were of the Bonsmara type, followed by Brahman, Nguni and smaller numbers of Afrikaner, Angus and Hereford types of cattle. Friesland was the only breed type in which a larger proportion of cows were slaughtered compared with bulls, because of the inherent nature of dairy farming and selection practices, which affect the composition of dairy cattle herds.

Table 1 Cattle breeds and proportions of sexes of the cattle slaughtered at the abattoir

\begin{tabular}{|c|c|c|c|}
\hline Breed & Sex & $\mathrm{N}$ & Proportion (\%) \\
\hline \multirow[t]{2}{*}{ Bonsmara } & Male & 10406 & 77.9 \\
\hline & Female & 2947 & 22.1 \\
\hline \multirow[t]{2}{*}{ Brahman } & Male & 4290 & 75.8 \\
\hline & Female & 1371 & 24.2 \\
\hline \multirow[t]{2}{*}{ Nguni } & Male & 1685 & 71.7 \\
\hline & Female & 665 & 28.3 \\
\hline \multirow[t]{2}{*}{ Afrikaner } & Male & 1691 & 75.1 \\
\hline & Female & 562 & 24.9 \\
\hline \multirow[t]{2}{*}{ Angus } & Male & 616 & 66.5 \\
\hline & Female & 310 & 33.5 \\
\hline \multirow[t]{2}{*}{ Hereford } & Male & 401 & 60.2 \\
\hline & Female & 265 & 39.8 \\
\hline \multirow[t]{2}{*}{ Friesland } & Male & 149 & 39.1 \\
\hline & Female & 232 & 60.9 \\
\hline
\end{tabular}

The cumulative incidence of partial and complete carcass condemnations during this study was $9.5 \%$, which resulted in an average carcass weight loss of $13.9 \pm 0.3 \%$ per condemned carcass (Table 2 ). A total of $0.6 \%$ of whole carcasses were condemned in this particular abattoir during the study. The most important causes of bovine carcass condemnations were peritonitis and pleuritis (2.9\%), soiling (2.5\%), and bruising $(2.2 \%)$. Almost half of the observed carcass condemnations were because of soiling and bruising, which can be addressed by implementing better abattoir management during transportation, pre-slaughter and lairage. These findings fit the Bradford Hill criteria in terms of specificity and biological plausibility, and indicate that greater exposure leads to a higher incidence of these condemnations.

The data presented in Table 2 indicated that $2.6 \%$ of all bovine carcasses that were diagnosed with peritonitis and pleuritis were trimmed (partial condemnation), while $0.3 \%$ of such carcasses were condemned. A total of $8.9 \%$ of carcasses diagnosed with diseases or defects could be trimmed, which 
resulted in a total carcass weight loss of $13.9 \%$ during the study. No carcasses were condemned because of soiling, bruising or wet carcass syndrome, while those diagnosed with measles were treated according to standard abattoir freezing protocols. All emaciated carcasses and those diagnosed with arthritis and jaundice were condemned.

The cumulative incidence of abscesses was less than $0.5 \%$, but $0.04 \%$ of abscessed carcasses were condemned. Those partially condemned resulted in weight loss of about $12.4 \%$ per carcass owing to cutting and trimming. These data are generally in agreement with those reported in Ethiopia with an incidence of abscesses in privately owned abattoirs of $0.06 \%$ (Mummed \& Webb, 2015). Although a larger proportion of carcass condemnations occurred in bulls compared with cows, with a higher incidence in the Bonsmara breed types, the data were skewed towards Bonsmara bulls, which generally predominate feedlot systems owing to an industry preference for those cattle types.

Table 2 Cumulative incidence percentage $( \pm S E)$ of peritonitis, pleuritis, soiling, bruising and parafilaria in carcasses, and of partial and whole carcass condemnations in beef carcasses sampled in a commercial cattle abattoir in South Africa

\begin{tabular}{lcccc}
\hline Disease/condition & $\begin{array}{c}\text { Cumulative } \\
\text { incidence }(\%)\end{array}$ & $\begin{array}{c}\text { \% Partial } \\
\text { carcasses } \\
\text { condemned }\end{array}$ & $\begin{array}{c}\text { \% Weight loss } \\
\text { per carcass }\end{array}$ & $\begin{array}{c}\text { \% Whole carcass } \\
\text { condemned }\end{array}$ \\
\hline Peritonitis and pleuritis & $2.91 \pm 0.175$ & $2.60 \pm 0.017$ & $13.9 \pm 0.661$ & $0.31 \pm 0.005$ \\
Soiling & $2.45 \pm 0.138$ & $2.43 \pm 0.138$ & $10.9 \pm 0.603$ & $0.02 \pm 0.017$ \\
Bruising & $2.19 \pm 0.149$ & $2.19 \pm 0.149$ & $16.4 \pm 0.601$ & 0 \\
Parafilaria & $0.55 \pm 0.075$ & $0.55 \pm 0.075$ & $7.5 \pm 1.221$ & 0 \\
Abscesses & $0.42 \pm 0.044$ & $0.38 \pm 0.012$ & $12.4 \pm 1.655$ & $0.039 \pm 0.012$ \\
Intramuscular haemorrhage & $0.34 \pm 0.051$ & $0.27 \pm 0.051$ & $30.6 \pm 2.903$ & $0.065 \pm 0.034$ \\
Oedema & $0.33 \pm 0.299$ & $0.30 \pm 0.037$ & $15.5 \pm 1.882$ & $0.027 \pm 0.010$ \\
Wet carcass syndrome & $0.15 \pm 0.036$ & $0.15 \pm 0.036$ & $15.9 \pm 2.691$ & 0 \\
Measles & $0.09 \pm 0.021$ & $0.09 \pm 0.021$ & - & 0 \\
Arthritis & $0.07 \pm 0.017$ & 0 & - & $0.072 \pm 0.017$ \\
Jaundice & $0.05 \pm 0.009$ & 0 & - & $0.023 \pm 0.009$ \\
Emaciated & $0.01 \pm 0.009$ & 0 & - & $0.015 \pm 0.009$ \\
Total condemnations & 9.5 & 8.9 & & 0.57 \\
& & & &
\end{tabular}

The overall cumulative incidence of soiling in bovine carcasses was $2.45 \%$, which caused $2.43 \%$ partial carcass condemnations of about $10.9 \%$ weight loss per carcass, although only about $0.02 \%$ of such carcasses were completely condemned. The incidence of soiling was more prevalent in bulls (80.7\% of diagnosed cases) compared with heifers (19.3\% of diagnosed cases), while Friesland cattle (1.84\%) were relatively unaffected by this condition $(P<0.05)$.

During the study unskilled labourers did the evisceration of carcasses (some using only one knife instead of the 'two-knife and three-knife protocols'). Improper handling of the cattle occurred, and the lairage facility was not properly washed before slaughter, all of which contributed to contamination and a greater number of partial carcass condemnations and eventually greater production losses. Soiling was the second most important cause of partial carcass condemnations and could reasonably be addressed by better abattoir management. The visceral contents were not a significant source of carcass contamination, but perforating viscera by inexperienced slaughter personnel normally causes soiling. In contrast, the transfer of contamination from hides to carcass surfaces is unavoidable owing to the nature of the skinning and removal process.

The overall cumulative incidence of bruising in carcasses during the study was about $2.19 \%$, which resulted in the second highest percentage of trimming (partial carcass condemnation) per affected carcass of $16.4 \%$ weight loss. Bruising did not result in whole carcass condemnation. The main reasons recorded for carcass bruising included aggressiveness of certain breed types, stress associated with confinement, and 
poor handling facilities. Bonsmara and Brahman were significantly more affected by bruising compared with Hereford $(P<0.05)$. Transportation may explain some less recent bruising, especially in breed types with horns.

Although a numerically lower number of cases of bruising was recorded in autumn compared with the other seasons, the differences were not statistically significant (Table 3). In Australian beef cattle, external factors (i.e. origin of animals, transport and handling) were responsible for the site where bruises are located on the body of the animal, whereas animal factors such as presence of horns, sex class and temperature may have determined the severity of bruising and may cause deeper lesions (Anderson \& Horder, 1979). These findings are explained by the 'strength' and 'consistency' criteria of Bradford-Hill (Hill, 1965), since higher condemnation and the consistent prevalence of contamination result from the nature of the slaughtering process. The cumulative incidence of parafilaria in bovine carcasses during the study was about $0.55 \%$.

Table 3 Influence of season on the cumulative incidence (means \pm SD) of carcass trimmings and condemnations in a commercial cattle abattoir in South Africa

\begin{tabular}{|c|c|c|c|c|}
\hline \multirow{2}{*}{ Condition } & \multicolumn{4}{|c|}{ Season } \\
\hline & Autumn & Winter & Spring \& Summer & $P$-value \\
\hline \multicolumn{5}{|c|}{ Peritonitis and pleuritis } \\
\hline$\%$ Trimmed & $2.60 \pm 1.566$ & $2.45 \pm 1.232$ & $2.75 \pm 1.485$ & NS \\
\hline$\%$ Condemned & $0.01 \pm 0.057$ & 0 & $0.01 \pm 0.06$ & NS \\
\hline \multicolumn{5}{|l|}{ Soiling } \\
\hline$\%$ Trimmed & $2.09 \pm 0.966$ & $2.29 \pm 0.824$ & $2.88 \pm 1.362$ & NS \\
\hline$\%$ Condemned & 0 & 0 & $0.06 \pm 0.239$ & NS \\
\hline \multicolumn{5}{|l|}{ Bruising } \\
\hline$\%$ Trimmed & $1.63 \pm 0.588$ & $2.46 \pm 1.127$ & $2.44 \pm 1.529$ & NS \\
\hline \multicolumn{5}{|l|}{ Parafilaria } \\
\hline$\%$ Trimmed & $0.42 \pm 0.37^{\mathrm{a}}$ & $0.24^{\mathrm{a}} \pm 0.26$ & $0.98^{\mathrm{b}} \pm 0.779$ & 0.002 \\
\hline \multicolumn{5}{|l|}{ Abscesses } \\
\hline$\%$ Trimmed & $0.31 \pm 0.336$ & $0.47 \pm 0.428$ & $0.36 \pm 0.287$ & NS \\
\hline$\%$ Condemned & 0 & $0.06 \pm 0.137$ & $0.04 \pm 0.106$ & NS \\
\hline \multicolumn{5}{|c|}{ Intramuscular haemorrhage } \\
\hline \%Trimmed & $0.07^{\mathrm{a}} \pm 0.197$ & $0.60^{b} \pm 0.487$ & $0.13^{a} \pm 0.307$ & 0.001 \\
\hline \%Condemned & 0 & 0 & $0.19 \pm 0.458$ & NS \\
\hline \multicolumn{5}{|l|}{ Oedema } \\
\hline$\%$ Trimmed & $0.35 \pm 0.381$ & $0.23 \pm 0.22$ & $0.32 \pm 0.270$ & NS \\
\hline$\%$ Condemned & $0.01 \pm 0.057$ & $0.02 \pm 0.072$ & $0.04 \pm 0.105$ & NS \\
\hline \multicolumn{5}{|c|}{ Wet carcass syndrome } \\
\hline$\%$ Trimmed & $0.12^{a} \pm 0.194$ & $0.32^{b} \pm 0.411$ & $0.02^{a} \pm 0.078$ & 0.05 \\
\hline \multicolumn{5}{|l|}{ Measles } \\
\hline$\%$ Treated & $0.02^{\mathrm{a}} \pm 0.084$ & $0.21^{b} \pm 0.237$ & $0.03^{a} \pm 0.088$ & 0.001 \\
\hline \multicolumn{5}{|l|}{ Arthritis } \\
\hline$\%$ Condemned & $0.05 \pm 0.129$ & $0.06 \pm 0.133$ & $0.09 \pm 0.169$ & NS \\
\hline \multicolumn{5}{|l|}{ Jaundice } \\
\hline$\%$ Condemned & $0.05 \pm 0.105$ & 0 & $0.02 \pm 0.073$ & NS \\
\hline \multicolumn{5}{|l|}{ Emaciated } \\
\hline$\%$ Condemned & $0.01 \pm 0.052$ & 0 & $0.03 \pm 0.116$ & NS \\
\hline
\end{tabular}


Parafilaria is caused by filarial nematode Parafilaria bovicola which manifests as cutaneous bleeding (mostly on dorsal parts of cattle), and severe lesions in the subcutaneous and intramuscular surfaces (BechNielsen et al., 1982). A higher number of cases of parafilaria were observed and recorded in summer, compared with autumn and winter $(P<0.01)$ (Table 3$)$. The higher cumulative incidence of parafilaria in summer was probably because cattle more frequently exposed to the parafilaria parasites in summer. The current data indicated that the number of cases decreased markedly in autumn, with infrequent cases in winter. Parafilaria has been identified as a source of considerable economic loss to the beef industry in South Africa and Sweden, despite the climatic differences between these countries. This disease occurs in the savannah areas in South Africa, mostly in summer as indicated, while in Sweden it has emerged as a problem in cattle following the spring turn out to pasture after winter housing (Merck Veterinary Manual, 2019). The data of the present study indicated that as much as $0.55 \%$ of each affected carcass might be condemned owing to carcass damage that is associated with parafilaria, which confirms the huge financial losses that are associated with this condition.

This relatively high cumulative incidence of parafilaria in the present study was surprising since the abattoir is not in a region that is typically affected by parafilaria parasites. However, cattle nowadays are transported over extraordinary distances for fattening in commercial feedlots in more centralized parts of the country and in closer proximity to the abattoir under investigation.

Other statistically significant causes of partial or whole carcass condemnations that were affected by season included intramuscular haemorrhage $(P<0.001)$, wet carcass syndrome $(P<0.05)$, and measles $(P$ $<0.001$ ) (Table 3). Intramuscular haemorrhage occurred predominantly in winter, and caused major partial carcass condemnations of up to $30.6 \%$ of weight loss per affected carcass. Fortunately, the cumulative incidence of this condition was low (0.34\%) and did not result in whole carcass condemnation.

Wet carcass syndrome is a more recent addition to the list of possible causes of carcass condemnations (Webb \& Van Niekerk, 2011), and occurred mostly in winter $(P<0.05)$. Its incidence fits the aetiology of the condition that it generally occurs in poorly conditioned animals that yield smaller carcasses, typically in times of feed scarcity. The effects of season clearly fit the 'temporality' criterion of Hill (1965) for causation. Although no whole carcass condemnations were recorded owing to this condition, affected carcasses have been rejected outright by retailers. These were not quantified in this study. Measles was another concerning condition which occurred predominantly in winter $(P<0.001)$, but affected carcasses $(0.093 \%)$ were treated, and no whole carcass condemnations were recorded.

Based on recent findings that carcass size is increasing in South Africa (Agbeniga \& Webb, 2018) and the hypothesis that carcass size may affect carcass condemnation, regression analysis was performed between bovine carcass weight and percentage carcass weight loss owing to partial or whole carcass condemnation. The results indicate that a relatively small, but significant, proportion of the variation in production losses was explained by carcass weight $\left(R^{2}=0.17\right)$ (Figure 1). However, the mathematical equation is not linear, but follows a cubic function, which means that the proportion of carcass weight loss initially increases slowly with increasing carcass size and the rate of increase accelerates with increasing carcass weight.

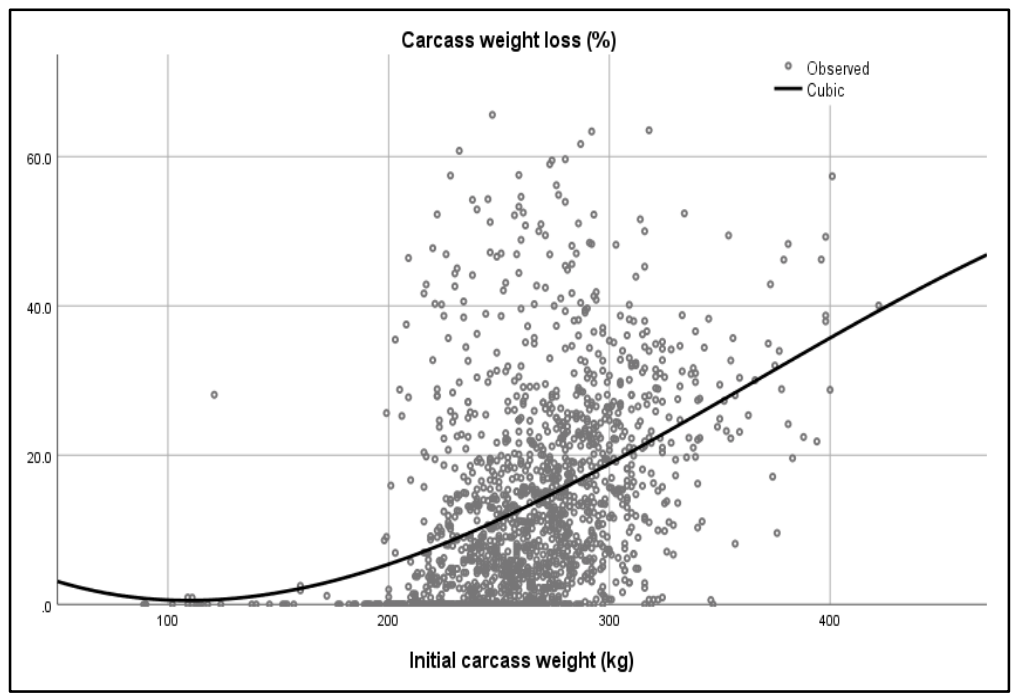

Figure 1 Effect of beef carcass weight on average percentage of carcass weight loss owing to partial carcass condemnations in a commercial cattle abattoir in South Africa 
The percentage of carcass weight losses over season (month of the year) was also analysed by regression (Figure 2) and confirms the observed seasonal effects $(P<0.001)$ on conditions such as parafilaria, intramuscular haemorrhage, wet carcass syndrome and measles, and the associated production losses.

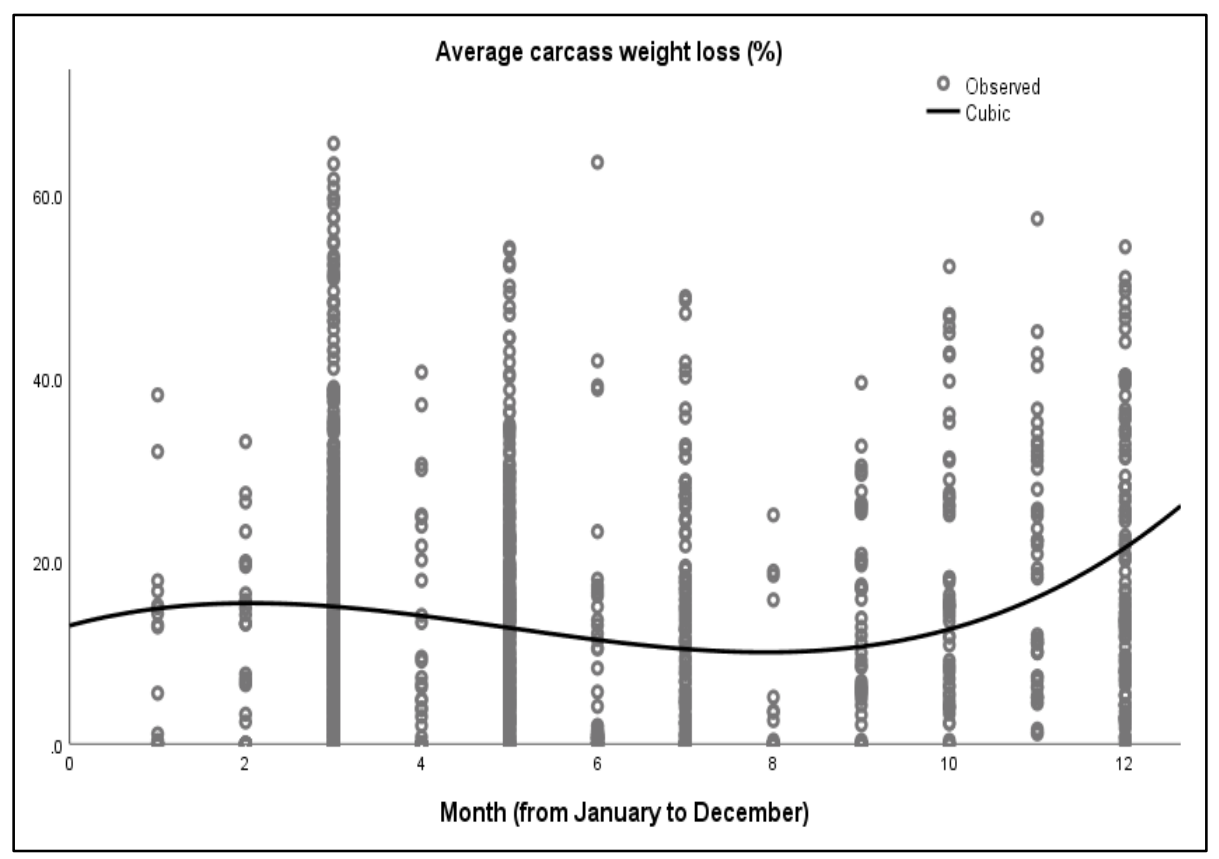

Figure 2 Influence of month of year on average percentage of carcass weight loss owing to partial carcass condemnations in a commercial cattle abattoir in South Africa

\section{Conclusion}

Cumulative incidence of carcass condemnations at a high throughput abattoir in South Africa was influenced by breed type, sex, and season. The prevalent conditions were peritonitis and pleuritis, soiling, bruising and parafilaria. Almost half of these carcass condemnations were due to soiling, which was more prevalent in summer, while bruising was more prevalent in winter. Carcass condemnations can be addressed by better transportation and abattoir management practices during lairage, pre-slaughter and post-mortem. Seasonal variations in certain carcass condemnations were demonstrated in this study. The higher cumulative incidence of parafilaria in summer may be due to cattle being more exposed to the parasites in summer. The results confirm that many of the Bradford-Hill criteria could be used to distinguish between associated factors and the more important causative factors of carcass condemnations.

\section{Acknowledgements}

The authors wish to thank Dr G.C. Neethling, manager of the Red Meat Abattoir Association for his support and advice. They would also like to thank the Meat Industry Trust of South Africa for funding the research project and the Department of Agriculture, Forestry and Fisheries for a study bursary to T. Thapi.

\section{Authors' Contributions}

The study was conceptualised by ECW and conducted by TT in collaboration with the Red Meat Abattoir Association (RMAA) and the International Meat Quality Assurance Services (IMQAS). Experimental planning and statistical analyses were conducted by ECW and EMW. The manuscript was written and edited by ECW and EMW.

\section{Conflict of Interest Declaration}

The authors declare that they have no conflicts of interest with regard to this work.

\section{References}

Agbeniga, B. \& Webb, E.C., 2018. Influence of carcass weight on meat quality of commercial feedlot steers with similar feedlot, slaughter and post-mortem management, Food Res. Int. 105, 793-800.

Alton, G.D., Pearl, D.L., Bateman, G.K., McNab, W.B. \& Berke, O., 2010. Factors associated with whole carcass condemnation rates in provincially inspected abattoirs in Ontario 2001-2007: Implications for food animal syndrome surveillance. BMC Vet. Res. 6, 42.

Anderson, B. \& Horder, J.C., 1979. The Australian carcass bruising scoring system. Queensl. Agric. J. 105, $281-287$. 
Bech-Nielsen, S, Bornstein, S., Christensson, D., Wallgren, T.B., Zakrisson, G. \& Chirico, J., 1982. Parafilaria bovicola (Tubangui 1934) in cattle: epizootiology - Vector studies and experimental transmission of Parafilaria bovicola to cattle. Am. J. Vet. Res. 43(6), 948-954.

Blackshaw, J.K., Blackshaw, A.W. \& Kusano, T., 1987. Cattle behaviour in a sale yard and its potential to cause bruising. Aust. J. Exp. Agric. 2(6), 753-757. https://doi.org/10.1071/EA9870753

Bogh-Sorensen, L., 1980. Product temperatures in chilled cabinet. Proceedings of the 26th European Meeting of Meat Research, Colorado Springs, USA.

Eilers, J.D., Tatum, J.D., Morgan, J.B. \& Smith, G.C., 1993. Quality losses due to producer related problems from cattle in the Strategic Alliance Field Study. Final Report of Colorado State University Portion of Strategic Alliance Field Study to the National Cattlemen's Beef Association. Department of Animal Sciences, Colorado State University, Ford Collins. pp.1-53.

Gallo, C., Lizondo, G. \& Knowles, T.G., 2003. Effects of journey and lairage time on steers transported to slaughter in Chile. Vet. Rec. 152, 361-364

Grandin, T., 1989. Behavioural principles of livestock handling. American Registry of Professional Animal Scientists. pp. 1-11. https://www.grandin.com/references/new.corral.html

Grigor, P.N., Goddard, P.J., MacDonald, A.J., Brown, S.N., Fawcett, A.R., Deakin, D.W. \& Warriss, P.D., 1997. Effects of duration of lairage following transportation on the behaviour and physiology of farmed red deer. Vet. Rec. 140, 812.

Hill, A.B., 1965. The environment and disease: Association or causation? Proc. R. Soc. Med. 58(5), 295-300.

Mach, N., Bach, A., Velarde, A. \& Devant, M., 2008. Association between animal, transportation, slaughterhouse practices, and meat $\mathrm{pH}$ in beef, Meat Sci. 78, 232-238.

McFadden, A.M., Christensen, H., Fairley, R.A., Hill, F.I., Gill, J.M., Keeling, S.E. \& Spence, R.P., 2011. Outbreaks of pleuritis and peritonitis in calves associated with Pasteurella multocida capsular type B strain. N.Z. Vet. J. 59(10), 40-45.

Meat Safety Act 40 of 2000. National Department of Agriculture. www.nda.agric.co.za

Merck Veterinary Manual. http://www.merckvetmanual.com. Accessed 25 June 2019.

Minka, N.S. \& Ayob, J.O., 2007. Effects of loading behaviour and road transport stress on traumatic injuries in cattle transported by road during the hot-dry season. Livest. Prod. Sci. 107, 91-95.

Mohammed, N., Hailemariam, Z. \& Mindaye, S., 2012. Major cause of liver condemnation and associated financial loss at Kombolcha Elfora Abattoir, South Wollo, Ethiopia. Eur. J. Appl. Sci. 4(4), 140-145.

Mummed, Y.Y. \& Webb, E.C., 2015. Causes of beef carcass and organ condemnations in Ethiopia, Asian J. Anim. Vet. Adv. 10(4), 147-160.

Phillips, C.J., 1993. Cattle behaviour. Farming Press Books, Wharfdale Rd, Ipswich, UK.

Schaefer, A.L., Jones, S.D. \& Stanley, R.W., 1997. The use of electrolyte solutions for reducing transport stress. J. Anim. Sci. 75(1), 258-265.

Smith, D.L. \& Wilson, L.L., 2000. Effect of transportation and electrolyte administration on lamb, pig and calf behavior, distress and performance traits. Department of Dairy and Animal Science, The Pennsylvania State University Park, PA pp.1-19

Van Der Walt, J.E., 2005. Microbiological quality of raw fresh beef post harvesting. Meat Sci., 21, 96-121.

Warriss, P.D., Brown, S.N., Knowles, T.G., Kestin, S.C., Edwards, J.E., Dolan, S.K. \& Phillips, A.J.,1995. Effects on cattle of transport by road for up to 15 hours, Vet. Rec. 136(13), 319-323.

Webb, E.C. \& Van Niekerk, W.A., 2011. Occurrence and aetiology of the 'wet carcass syndrome' in sheep in southern Africa. Proceedings of 57th International Conference of Meat Science and Technology, Ghent, Belgium https://www.ncbi.nlm.nih.gov/pubmed/22081816 